\title{
Structuring information from BIM: A glance at bills of materials
}

\author{
J. Mukkavaara ${ }^{\mathrm{a}}$, G. Jansson ${ }^{\mathrm{a}}$ and T. Olofsson ${ }^{\mathrm{a}}$ \\ ${ }^{a}$ Department of Civil, Environmental and Natural Resources Engineering, Luleå University of Technology, Sweden \\ E-mail: jani.mukkavaara@ltu.se, gustav.jansson@ltu.se, thomas.olofsson@ltu.se
}

\begin{abstract}
Industrialized house-builders are moving towards an enhanced production where management of information along the value chain is critical in order to deliver housing projects on time and with the desired quality. Today digital tools and systems are used in both design and production to produce, deliver and instruct actors throughout the phases of a project. However, the information usually exists in different islands and manual transfers are required to keep the flow of information between IT-systems and individuals continuous. A key to improving the ability for the members in different stages of a project to work with the same information is to facilitate different views. One of the building blocks for creating bridges between the islands of information is to introduce bills of materials which can be used to organize information for different purposes. Uniting the use of building information modeling (BIM) with bills of materials (BOM) is therefore our focus in this paper. This is done in the context of industrialized house-building and the facets which it brings to the subject. The aim of this paper is to present an early endeavor into a BOM based approach for structuring information from BIM models. A demonstration tool was developed, and together with application in a case project from an industrialized house-builder, the generation of BOMs from BIM data is illustrated and discussed. The findings illustrates that we can apply different structures to the information located in our BIM models and that we can produce a BOM perspective on our products. Also, it is highlighted that we still need further studies to better understand how application of BOMs in the context of industrialized house-building is realized.
\end{abstract}

Keywords -

Bill of Materials; BIM; Industrialized; HouseBuilding

\section{Introduction}

Within the realm of industrialized house-building the use of information and communications technology (ICT) is a facilitator providing conditions for an efficient production with accurate and reliable information [1]. Using ICT to share and provide up-to-date information along the value chain becomes an essential part in effective housing production processes. However, as a house-building project progresses, information is at risk to become fragmented into islands. Use of different tools by actors coupled with requirements on diverse views on information lead to implications where manual transfers between these islands becomes common in order to retain the flow of information. Solutions to this fragmentation has been discussed from angles including using a central repository to achieve greater integration [2] and using the common format of IFC to facilitate information exchange [3]. Within these, Building Information Modeling (BIM) is used as the overarching method and has been highlighted as an assistant in in solving these issues [4]. Furthermore, matters regarding integration, collaboration and information sharing in the context of BIM has also received increased attention in recent research [5].

It could be argued that as industrialized housebuilding companies retain more control of the value chain, leading to less fragmentation, there are greater chances of success when integrating ICT [6,7]. Despite this, issues exists including the overall management of information [8]. With characteristics from both the construction and manufacturing industry, adopting established practices from the latter has been of interest. As such, attention has been placed on adopting tools and methods, such as Enterprise Resource Planning (ERP) [7] and Product Lifecycle Management (PLM) [9]. However, ICT-tools adopted from other contexts have been targeted as one of the hindrances as these may not be optimal for their new context $[6,8,9]$. Issues that are present include divergent data structures that interfere with bridging of systems [6,8], and a dissimilarity in the view on projects [9] and construction objects [7]. For accommodating different views on information and to provide product structures through the lifecycle of a product, bill of materials (BOM) is described as a key facilitator [10]. The BOM carries product data between actors and systems, and is an essential part in the ICT toolkit. Previous research on information management 
within industrialized house-building has however paid little attention to the use of bills of materials as an approach to structuring information. Difficulties in managing information through the value chain, and requiring diverse views on information are however persistent issues. Better maintaining a continuous flow of information, providing accurate and reliable information between actors and tools, are aspects to strive for and to further explore. Therefore, the aim of this paper is to present an early endeavour of uniting the concepts of $\mathrm{BIM}$ and BOM in the context of industrialized housebuilding, suggesting a BOM based approach for structuring information. This approach is exemplified through a case study with a demonstration tool that extends a BIM capable platform to provide a BOM perspective on BIM data. The contribution of this study aim to start setting the groundwork for further studies regarding using BOM as a means to structure information in the context of industrialized house-building.

\section{Background}

\subsection{Industrialized House-Building and ICT}

The Swedish housing sector has been subject to an expansive development of industrialized methods. A strive towards shorter lead times, quality of deliveries, and customized buildings are driving forces for house builders to systemize work in their supply chains. Here, industrialized house-building is used to describe methods and principles of a process- and product-oriented alternative to traditional project-oriented house-building [11]. Constructs that constitute industrialized housebuilding includes management of components, processes and relations in the standardization of house-building platforms, as well as development of ICT for integration. Thus, the ability to provide up-to-date information [7], which is accurate and reliable [1] are key contributions from ICT to an efficient production. With characteristics from both the construction and the manufacturing industry, efforts to adopt patterns from the latter has been previously studied. Ekholm and Molnár [12] highlighted that information systems known from the manufacturing industry have been integrated in the industrialization of the building sector in order to reap from the benefits it has shown. Babič et al [7] investigated creating a link between an Enterprise Resource Planning (ERP) system and BIM. Holzer [13] investigated approaches to create links between Product Lifecycle Management (PLM) systems, together with BIM, to provide information to ERP-systems.

Through a perspective of BIM being used throughout a building's lifecycle, with the resulting information rich model, it becomes a facilitator for information management. With this, a growing interest has been shown areas of collaboration, information sharing, and integration [5]. Through this continuing expansion of BIM as an ICT platform, some research has surfaced investigating the relation between the areas of industrialized house-building and BIM. Lu and Korman [14] discussed benefits and challenges of BIM for modular construction from a perspective of pre-project planning and coordination. Moghadam et al [15] proposed a model for modular construction manufacturing that links BIM and lean. Lu et al [16] presented a BIM-based trade-off platform for industrialized housing. Nawari [17] proposed an information delivery manual for off-site construction. Ezcan et al [18] showed interest in BIM and off-site manufacturing and indicated that it would contribute in areas of IT integration, providing extensive information and improving lead times to mention a few.

\subsection{Bills of Materials}

At the heart of information systems within the manufacturing industry is the bill of materials (BOM) [19]. This includes systems like MRP (Material Resource Planning), ERP (Enterprise Resource Planning) and PDM (Product Data Management) [10,20]. Throughout the lifecycle of a product, it is used to accommodate different views on information and to provide data structures [10]. There are more than one way to define BOM and three different distinctions are described here: 1) as an organized collection of quantities, 2) as a means to structure information in systems, and 3) as a data repository.

When viewed in its simplest form the BOM provides a collection of the materials and components that comprise a product, together with the required quantities [21]. In a similar vein, and more commonly discussed in the construction industry, is quantity takeoff that offers the amount of materials and components which can be organized into a bill of quantities [21]. Further developments of the BOM exist where it is seen as a product specification, describing the composition of a product and how it is realized from its immediate components [19]. In these extended perspectives, more emphasis is put on the relationships between components (children) and their parents. As such, it becomes decoupled from being the sibling of quantity takeoff, and is instead transformed into a description of how a product is configured. Another take on the BOM exists where it is not only viewed as the underlying structure, but also as an information repository. Some authors describe the $\mathrm{BOM}$ as a "product structure data file" [23] or a "database" [24]. The scope of the BOM is thus extended to contain a wide variety of information, e.g. product specifications, part drawings, parts routing, manufacturing processes etc. [24].

A key part in the use of BOMs throughout multiple 
phases of a product's lifecycle is the different views that can be applied dependent on the use case and activities associated. The Engineering BOM (E-BOM) and the Manufacturing BOM (M-BOM) are two commonly discussed $[20,21,24]$. The E-BOM is used by designers [21], representing a product from an engineering viewpoint of how the product is functionally formed, however lacking sufficient information regarding manufacturing [25]. This is mitigated by the M-BOM which is a representation of a product based on how it is manufactured [25]. In a more practical sense, the E-BOM is usually managed through a CAD system, where support is provided for the designers to represent their product structure according to their desires. Furthermore, the $\mathrm{M}-\mathrm{BOM}$ is the result of a transformation of the EBOM where additional aspects are included such as manufacturing sequence [25], and adding interim assemblies to better depict the manufacturing process. As such, despite describing the same product, these different BOMs manifest themselves with different structures (see Figure 1), providing each phase of a product with the necessary information.

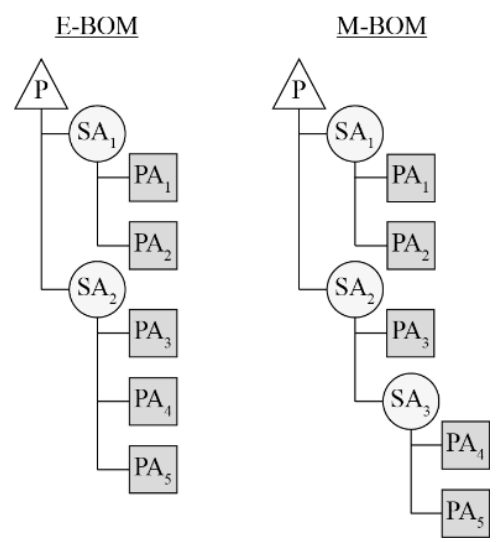

Figure 1. Example structure of an E-BOM and M$\mathrm{BOM}$, where $\mathrm{P}$ is the product, $\mathrm{SA}$ is a subassembly and PA is a part (adapted from [20])

Some authors (e.g. [20,26]) have also chosen to differentiate between the usage of BOMs, and the structural representation of BOMs. In these cases, the usage includes for example the E-BOM and the M-BOM. The structural representation includes for example the Traditional BOM, the Modular BOM [27], and the Generic BOM [19]. These different structures exists as Traditional BOM structures might bring issues to companies with large product offerings. As such, application of different structural representations is done to better support different production strategies, such as having high variety offerings or modular product compositions.

\section{Generating BOMs from BIM data}

\subsection{Research approach}

In this research, a review of earlier research was used to motivate the gap and to serve as input for the proposed approach. Following, a demonstration tool was developed in order to exemplify the restructuring of BIM data from a BOM perspective. In order to provide an illustration of the approach in a real-world setting, a case project was then used where an application of the demonstration tool is provided. The case project was chosen from an industrialized house-builder in Sweden, who focuses on production of residential housing. The company applies modular construction using lightweight timber frames, complemented with insulation materials and covered with sheathing. Each building is broken down into individual modules which are produced to an almost finished state off-site in a factory, to later be assembled and finished on-site. The case project in question is comprised of 156 modules, and the building ranges from 5 to 10 stories.

As a foundation, and for providing a BIM capable platform which provides a source for the necessary BIM data, Autodesk Revit was used. In order to enable representation of timber framed structures in Autodesk Revit, the add-in MWF Pro Wood [28] was used which in this instance provided design automation capabilities for framing timber walls. The demonstration tool was developed as an add-in to Autodesk Revit written in C\#, utilizing access to Autodesk Revit's API to grant access to the data stored within the BIM model. The demonstration tool is composed of three main parts: configuration, generation, and delivery.

The perspective on BOM that is adopted in this paper is targeted towards providing a product specification, with focus on promoting the product composition [19] using product, subassemblies and parts as seen in Figure 1. Among the different views each BOM can encompass, this paper will concentrate on providing an engineering perspective, also denoted as the E-BOM [21]. This is done through using information found in a BIM model which is used as input to the demonstration tool. The underlying structure that is generated in the E-BOM is based on a Traditional BOM structure.

\subsection{Demonstration of BOM generation}

\subsubsection{BIM model}

With the demonstration tool in need for input data, A BIM model was created for the case project using Autodesk Revit (see Figure 2) based on 2D drawings provided by the case company. Using commonly available tools in Autodesk Revit, walls, floors, ceilings, doors, and windows were modeled. In addition, using the 
MWF Pro Wood add-in, the specified technical solutions for each of the wall types was configured. Through that, studs and sheathings for the exterior and interior walls were automatically generated. As the case project in question is constructed using a modular production strategy, measures were taken in order to represent these modules in the BIM model. To achieve this representation spaces were used as objects to define and provide the boundaries of each module. Except for providing a possibility to include the modules in the BOM, these spaces are also later used in cases where relationships between elements and modules needs to be derived. The floors and ceilings did not receive joists and sheathing but were modeled using their corresponding element types in Autodesk Revit. Furthermore, elements not included in the BIM model was the roof (including trusses), the concrete foundation, and MEP.
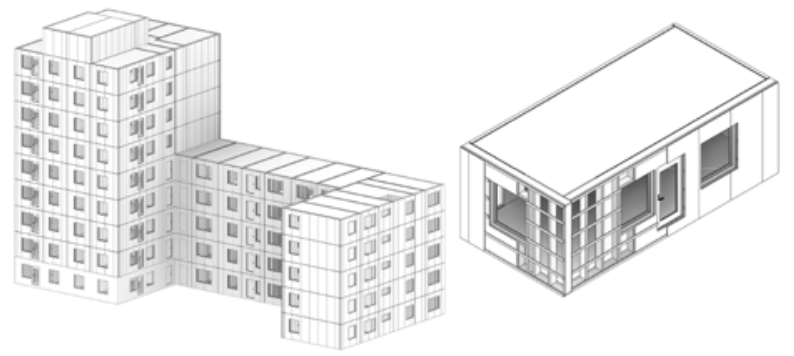

Figure 2. 3D-view of the created BIM-model for the case project with a close up of an individual module showing parts of the studs and sheathing.

\subsubsection{Configuration}

The first part of the demonstration tool is the configuration stage. Here, a number of options are made available regarding the composition of the BOM, and these choices will act as a basis for the generation of the BOM. The ability is provided to choose what categories will be included, which is this demonstration is bound to project, levels, modules, walls, floors, ceilings, windows, doors, studs, and sheathing. These categories correspond to some of the different categories provided when modeling in Autodesk Revit, and in extension also when using MWF Pro Wood. They also correspond to categories commonly used in timber frame modular construction. Besides selecting the categories of interest, a hierarchical structure can be decided upon by dragging and dropping objects in the tree view. This hierarchical structure determines the parent-child relationship between the categories which will be present in the BOM and describes the product, the subassemblies and the parts. As a category is placed as a child to another, the succeeding generation step will attempt to solve this relationship for each individual instance of that category.

Besides choosing objects and hierarchy, a selection of what attributes from each category should represent the tags is provided. These include using the instance name or family type that is automatically attached to each element in Autodesk Revit, or using the user-defined instance attribute Mark. These tags are later used as labels for each entry in the generated BOM. The purpose of them is to provide a human-readable designation, rather than just using the unique id of each element. It can also be decided if entries in the BOM should be grouped together. It might not always be necessary to include each instance of all categories, so grouping based on type or category is provided as an option. As such, it could be decided that e.g. instead of including each stud as separate entries, they are grouped together based on their type.

For the case project all available elements were selected and organized in a hierarchy as seen in Figure 3. Each category was given an appropriate tag, in this case mainly the type name. Furthermore, options for the groupings were configured such that the major categories are to be kept as instances whereas the individual components (such as studs) are grouped by their type. This configuration was selected with a modular design in mind. As such, with each module, and each wall, being produced individually, this configuration enables the tracing of the constituent elements.

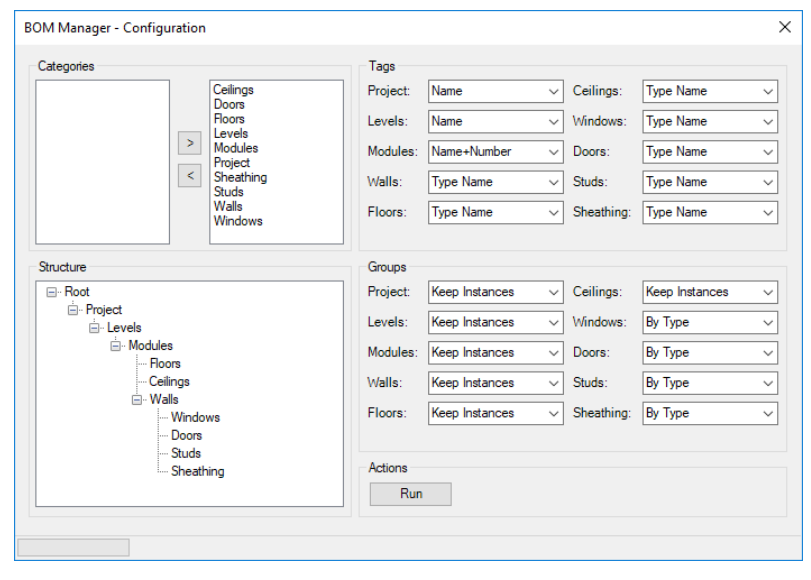

Figure 3. Configuration of the case study project within the demonstration tool.

\subsubsection{Generation}

With the configuration done, the BOM can be generated based on the input and BIM data available. At the start of the generation all elements are collected from the different categories that was selected. This entails using calls to Autodesk Revit's API in order to fetch each element instance of all selected categories. After the objects have been gathered, further calls to Autodesk Revit's API are made in order to extract the attribute values that correspond to the tags that were chosen for 
each category respectively, e.g. using the type name.

With the elements collected, it now needs to generate the hierarchy decided in the configuration stage. Depending on the specific relationship situation, this is done either geometrically or through attributes. Autodesk Revit already stores some of these relationships in attributes, for example what level a floor belongs to, or what wall a window is hosted by. The developed demonstration tool is however extending this to enable parent-child relationships between modules and elements, as well as between walls and studs or sheathing. As such, in the cases where there are no attributes to rely upon, a geometrical search is conducted. This is executed by taking an elements bounding box center point and iterating through the chosen parent category, searching for a match where that point is found within the boundaries of another element. If it is determined that a point falls within the boundaries of another element, it is established that a parent-child relationship has been found.

When all the relationships are found the elements are still represented as instances. The last step, if a configuration was chosen where certain categories are to be grouped based on their type or category, is therefore to process the groups. This is done by iterating through all levels of the hierarchy, gathering all siblings on each level and matching them by type or category. Here, it removes all entries of individual instances and replaces them with a group entry, representing a collection of instances.

\subsubsection{Delivery}

As the generation of the $\mathrm{BOM}$ is done, the last stage is to deliver it. A rudimentary viewer was therefore incorporated into the demonstration tool. In this viewer, the hierarchical structure is provided with a listing of the entries in the current BIM model. When an entry in the hierarchy is selected, the basic attributes of that entry is presented. This is done by accessing the attributes that was gathered during the generation of the BOM, but also by directly accessing attributes for the selected element in the BIM model. These attributes include the id, tag, and category of element together with a selection of category based attributes (e.g. dimensions of an element). Alongside this presentation of the BOM, an option is also provided to either export the entire BOM to an Exceldocument, or a selection of it. The latter of these exports only the selected entries and its children, excluding the rest.

For the case project a representation of the BOM in the viewer can be seen in Figure 4. Here, the hierarchical functionality is displayed where the constituent elements in individual modules, and individual walls, can be examined. Each entry is also labeled according to their name or type name. Also, a display of attributes which are gathered from the BIM model is shown. The corresponding structure can be seen in the exported Excel document containing the entire BOM hierarchy (see Figure 5).

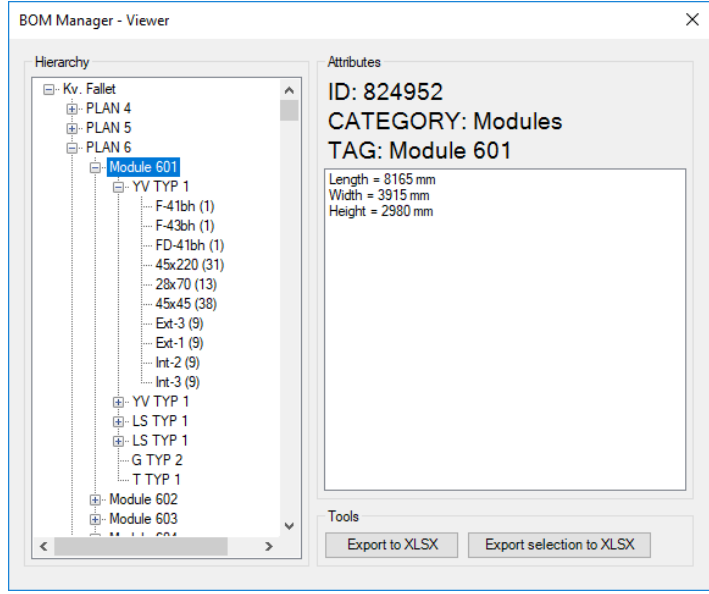

Figure 4. Viewer with the generated BOM for the case study project within the demonstration tool.

\begin{tabular}{|c|c|c|c|c|c|}
\hline$\Delta$ & A & B & c & D & E \\
\hline 1 & Hierarchy & Tag & Category & & \\
\hline 2 & 1 & Kv. Fallet & Project & & \\
\hline 3 & 1.1 & PLAN 4 & Levels & & \\
\hline 4 & 1.1.1 & Module 401 & Modules & & \\
\hline 5 & 1.1.1.1 & YV TYP 1 & Walls & & \\
\hline 6 & 1.1.1.1.1 & F-41bh (1) & Windows & & \\
\hline 7 & 1.1.1.1.2 & F-43bh (1) & Windows & & \\
\hline 8 & 1.1.1.1.3 & FD-41bh (1) & Doors & & \\
\hline 9 & 1.1.1.1.4 & $45 \times 220(31)$ & Studs & & \\
\hline 10 & 1.1.1.1.5 & $28 \times 70(13)$ & Studs & & \\
\hline 11 & 1.1.1.1.6 & $45 \times 45$ (38) & Studs & & \\
\hline 12 & 1.1.1.1.7 & Ext-3 (9) & Sheathing & & \\
\hline 13 & 1.1.1.1.8 & Ext-1 (9) & Sheathing & & \\
\hline 14 & 1.1.1.1.9 & Int-2 (9) & Sheathing & & \\
\hline 15 & 1.1.1.1.10 & Int-3 (9) & Sheathing & & \\
\hline 16 & 1.1.1.2 & YV TYP 1 & Walls & & \\
\hline
\end{tabular}

Figure 5. Part of the Excel document exported from the generated BOM for the case study.

\section{Discussion and conclusion}

Issues of managing information and enabling diverse views on information are present within industrialized house-building. Using bills of materials (BOM) as an underlying structure for managing information during a products lifecycle has previously been seen in the manufacturing industry, where it is often built into CAD tools, and supported by PLM and ERP systems. With industrialized house-builders sharing some of the characteristics of the more product-oriented manufacturing industry, approaching information management from a BOM oriented perspective was of interest in this study. As such, this insight was adopted in an effort to generate a BOM based on BIM data. In a 
demonstration tool, using BIM data as the input, a parentchild hierarchy with links to attributes was generated based on a chosen configuration. This output resulted in providing an engineering view on the BOM, referred to as an E-BOM. This has also been presented when applied on a case of a multi-family residential housing project from an industrialized house-builder. The results shows how the BOM provides a view of a building based on its composition, and in the case study shows how individual modules and walls are composed.

Compared to approaching information management from a central repository [2] or IFC [3] perspective, the use of BOM is in this instance not seen as an overarching solution. It is rather seen from the viewpoint of being a method which can be applied to create an underlying structure to describe a product [19]. The question as such is not how we transfer information between systems, but rather how we describe our product in a way that facilitates this information transfer. Having a unified structure for our products is a step in that direction, and BOM is a method which could be used to aid this.

The presented demonstration tool shows an after-thefact implementation of BOM generation. However, as more commonly seen in CAD tools from other industries, the use of BOM is an integrated part of the work flow for designers and engineers. As such, for adoption within industrialized house-builders, the questions of who creates the BOM and when are relevant.

This study shows a demonstration where an E-BOM is generated, using a traditional BOM structure. One of the strengths of BOM is however the ability to adapt to different views depending on the application. As such, further studies are of interest where the E-BOM is not only generated, but also transformed into other forms, such as the M-BOM to support manufacturing. Furthermore, with the use of product platforms and a product-oriented perspective, industrialized housebuilders using predefined solutions could benefit from using alternative structures, such as the Modular BOM, in efforts to more efficiently derive products. Furthermore, the composition chosen for the E-BOM in this study is limited to only showing one structure. If we are to follow the view of an E-BOM as a functional decomposition of a product, then there is a need to identify what that entails for the context of industrialized house-builders.

The concept of implementing BOMs in the context of industrialized house-builders is seen as showing promise in the search for methods by which we structure information in our IT-systems throughout the value chain. Its use in the manufacturing industry is described by previous research but in the context of industrialized house-building it is more of a novel approach. This study shows how an implementation could be performed where BIM data is used as an information base, however, this study is only a glance at the topic and there is a need for further studies to better describe its use in the context of industrialized house-builders. As such, future research should include topics such as: identifying the owner(s) and user(s) of BOMs, in order to know who defines them and how they are consumed; what different representations of BOMs (e.g. E-BOM, M-BOM) could be used and how they should be structured; how BOMs could be used to bridge IT-systems (e.g. BIM and PLM) in order to support design and production of houses.

\section{References}

[1] Lessing J. Industrialised house-building. Concept and Processes, Department of Construction Sciences, Lund University, 2006.

[2] Singh V., Gu N., and Wang X. A theoretical framework of a BIM-based multi-disciplinary collaboration platform. Automation in construction, 20(2):134-144, 2011.

[3] Fu C., Aouad G., Lee, A., Mashall-Ponting A., and $\mathrm{Wu}$ S. IFC model viewer to support $\mathrm{nD}$ model application. Automation in Construction, 15(2):178-185, 2006.

[4] Eastman C., Teicholz P. and Sacks R. BIM handbook: A guide to building information modeling for owners, managers, designers, engineers and contractors. John Wiley \& Sons, Hoboken, NJ, 2011.

[5] Santos R., Costa A. A. and Grilo A. Bibliometric analysis and review of Building Information Modelling literature published between 2005 and 2015. Automation in Construction, 80:118-136, 2017.

[6] Johnsson H., Malmgren L. and Persson S. ICT support for industrial production of houses: the Swedish case. In W78 Bringing ITC Knowledge to Work, pages 407-414, Maribor, Slovenia, 2007.

[7] Babič N. Č., Podbreznik P. and Rebolj D. Integrating resource production and construction using BIM. Automation in Construction, 19(5):539543, 2010.

[8] Persson S., Malmgren L., and Johnsson $H$. Information management in industrial housing design and manufacture. Journal of Information Technology in Construction, 14:110-122, 2009.

[9] Aram S. and Eastman C. Integration of PLM solutions and BIM systems for the AEC industry. In Proceedings of 30th International Symposium of Automation and Robotics in Construction and Mining, pages 1045-1055, Montréal, Canada, 2013.

[10] Lee C., Leem C. S., and Hwang I. PDM and ERP integration methodology using digital manufacturing to support global manufacturing. The International Journal of Advanced 
Manufacturing Technology, 53(1-4):399-409, 2011.

[11] Lessing J., Stehn L., and Ekholm, A. Industrialised house-building-development and conceptual orientation of the field. Construction Innovation, 15(3):378-399, 2015.

[12] Ekholm A., and Molnar M. ICT development strategies for industrialisation of the building sector. Journal of Information Technology in Construction, 14(28):429-444, 2009.

[13] Holzer D. Fostering the link from PLM to ERP via BIM. In IFIP International Conference on Product Lifecycle Management, pages 75-82, 2014.

[14] Lu N., and Korman T. Implementation of building information modeling (BIM) in modular construction: Benefits and challenges. In Construction Research Congress 2010: Innovation for Reshaping Construction Practice, pages 11361145, Banff, Alberta, Canada, 2010.

[15] Moghadam M., Alwisy A., and Al-Hussein M. Integrated BIM/Lean base production line schedule model for modular construction manufacturing. In Construction Research Congress 2012: Construction Challenges in a Flat World, pages 1271-1280, West Lafayette, Indiana, United States, 2012.

[16] Lu W., Olofsson T., Jensen P., \& Simonsson P. BIM-based lean-agile supply chain for industrialized housing. In Proceedings of the 11th International Conference on Construction Applications of Virtual Reality, pages 262-270. Weimar, Germany, 2011.

[17] Nawari N. O. BIM standard in off-site construction. Journal of Architectural Engineering, 18(2):107113, 2012.

[18] Ezcan V., Isikdag U., and Goulding J. S. BIM and off-site manufacturing: recent research and opportunities. In 19th CIB World Building Congress, Brisbane, Australia, 2013.

[19] Hegge H. M. H., and Wortmann J. C. Generic billof-material: a new product model. International Journal of Production Economics, 23(1-3):117-128, 1991.

[20] Jung S. Y., Kim B. H., Choi Y. J., and Choi H. Z. BOM-Centric Product Data Management for Small and Medium Manufacturing Enterprises. In Proceedings of the DESIGN 2014 13th International Design Conference, pages 1799-1810, Cavtat, Croatia, 2014.

[21] Chang S. H., Lee W. L., and Li R. K. Manufacturing bill-of-material planning. Production planning \& control, 8(5):437-450, 1997.

[22] Monteiro A., and Martins J. P. A survey on modeling guidelines for quantity takeoff-oriented BIM-based design. Automation in Construction, 35:238-253, 2013.
[23] Liu M., Lai J., and Shen W. A method for transformation of engineering bill of materials to maintenance bill of materials. Robotics and Computer-Integrated Manufacturing, 30(2):142149, 2014.

[24] Tozawa Y., and Yotsukura M. Integration of bills of material towards a communication tool. In 2009 WRI World Congress on Computer Science and Information Engineering, pages 446-450, Los Angeles, USA, 2009.

[25] Xu H. C., Xu X. F., and He T. Research on transformation engineering $\mathrm{BOM}$ into manufacturing BOM based on BOP. Applied Mechanics and Materials, 10-12:99-103, 2008.

[26] Lee J. H., and Lee J. Features of data management in PLM customised for ship design adopting engineering to order strategy. International Journal of Product Lifecycle Management, 7(4):292-317, 2014.

[27] Yao J. M., Lu C. H., and Wang Y. H. Implementation Techniques of Modular BOM in Automobile Flexible Manufacturing. In Advanced Materials Research, 988:739-744) 2014.

[28] StrucSoft Solutions. MWF Pro Wood. On-line: http://strucsoftsolutions.com/mwf-pro-wood, Accessed: 16/01/2018. 